\title{
基于线性叠氮四核单元的系列二维化合物：合成，晶体结构及磁性
}

\author{
李佐习杨乾李立存胡同亮* 卜显和 \\ (南开大学化学系 金属与分子基材料化学天津市重点实验室 天津 300071)
}

\begin{abstract}
摘要 分子磁体的设计与合成一直是当今物理和化学的热门研究课题. 受分子磁体启发, 通过引入叠氮磁耦合基团以 及长链棒状配体 4,4'-二咪唑联苯 (L), 我们构筑了三个磁性化合物 $\left.\left[\mathrm{Co}_{2}\left(\mathrm{~N}_{3}\right)_{4}(\mathrm{~L})_{2.5}\right]_{\infty}(\mathbf{1}), \mathrm{Ni}_{2}\left(\mathrm{~N}_{3}\right)_{3}\left(\mathrm{NO}_{3}\right)(\mathrm{L})_{2.5}\right]_{\infty}(\mathbf{2})$ 和 $\left[\mathrm{Mn}_{2}\left(\mathrm{~N}_{3}\right)_{4}(\mathrm{~L})_{2.5}\right]_{\infty}(3)$. 结构分析显示，这是三个同构化合物，展现了一种基于线性叠氮四核单元的二维层网络. 有意义 的是, 这种线性叠氮四核单元还未曾被人报道. 磁性研究表明, 三个化合物都是铁磁耦合, 这是由于 $E O$-叠氮所导致 的. 通过拟合实验数据, 我们得到了三个化合物的磁耦合常数, 进一步验证了上面磁构相关性的讨论.
\end{abstract}

关键词 配位聚合物; 棒状配体; 线性四核簇; 磁性

\section{A Series of 2D Coordination Polymers Based on Unprecedented Linear Tetranuclear Units Bridged by the Azido Anion: Syntheses, Crystal Structures and Magnetic Properties}

\author{
Li, Zuoxi Yang, Qian Li, Licun Hu, Tongliang* Bu, Xianhe \\ (Department of Chemistry, and Tianjin Key Laboratory of Metal \& Molecule-based Material Chemistry, Nankai University, \\ Tianjin 300071)
}

\begin{abstract}
Sparked by the strategy of molecular magnets, three magnetic coordination polymers, $\left[\mathrm{Co}_{2}\left(\mathrm{~N}_{3}\right)_{4}(\mathrm{~L})_{2.5}\right]_{\infty}(\mathbf{1})$, $\left[\mathrm{Ni}_{2}\left(\mathrm{~N}_{3}\right)_{3}\left(\mathrm{NO}_{3}\right)(\mathrm{L})_{2.5}\right]_{\infty}(2)$ and $\left[\mathrm{Mn}_{2}\left(\mathrm{~N}_{3}\right)_{4}(\mathrm{~L})_{2.5}\right]_{\infty}(3)$ ( $\mathrm{L}=4,4^{\prime}$-bis(imidazol-1-yl)biphenyl), have been synthesized by employing azide as the coupling carrier and a rod-like ligand $\mathrm{L}$ as the magnetic insulator. Structural analysis indicates that complexes $\mathbf{1} \sim \mathbf{3}$ are iso-structural, and illustrate a $2 \mathrm{D}(4,4)$ layer based on unprecedented linear tetranuclear units bridged by the $E O$-azido ions. Their magnetic measurements revealed that complexes $\mathbf{1} \sim \mathbf{3}$ all present the ferromagnetic (FM) coupling, which was due to the $E O$-azido linker. The corresponding exchange coupling constants have been estimated by fitting the experimental data, which confirmed the above magneto-structural correlations.

Keywords coordination polymer; rod-like ligand; linear tetranuclear cluster; magnetic property
\end{abstract}

\section{Introduction}

In recent years, magnetic coordination polymers have attracted a great deal of attention not only for their intriguing structural diversity, ${ }^{[1,2]}$ but also for their potential applications in high-density information storage devices, ${ }^{[3]}$ quantum computing devices ${ }^{[4]}$ and molecular spintronics. ${ }^{[5]}$ The developments of this area have been experiencing great success in creating a number of molecular magnets, such as single-molecule magnets, ${ }^{[6]}$ single-chain magnets ${ }^{[7]}$ and single-ion magnets. ${ }^{[8]}$ Moreover, construction of novel magnetic unit and the theoretical simulation have always been the research hotspots of magnetic chemistry. ${ }^{[9,10]}$

The azide anion $\mathrm{N}_{3}^{-}$is a three-atom bridge that can effectively mediate the magnetic coupling. Compared to other small multitopic ligands, such as $\mathrm{CN}^{-},{ }^{[11]} \mathrm{HCO}_{2}^{-},{ }^{[12]}$ and $\mathrm{C}_{2} \mathrm{O}_{4}^{2-},{ }^{[13]}$ the azide anion exhibits variety of bridging modes, such as $E O$ - and $E E$ - patterns, to link two or more transition-metal ions into clusters. ${ }^{[14-16]}$ Thus the azide anion provides a versatile "building block" for the construction of molecular magnetic materials.

In most cases, a suitable auxiliary ligand, such as long rod-like or bulky angle ligand, is mostly utilized to prevent 3D magnetic ordering, which would contribute to lowdimension magnetic units. ${ }^{[17,18]}$ As the linear long backbone to isolate magnetic units, the rigid bis(imidazole) ligands are good candidates for the exploration of magnetic materials. ${ }^{[19]}$ Furthermore, the coordination chemistry of bis(imidazole) ligands have been continuously explored in our group, and they are liable to afford magnetic materials owing to the coordination affinity. ${ }^{[20,21]}$ In light of these aspects, here, three iso-structural complexes by introducing $\mathrm{N}_{3}^{-}$into the systems of bivalent metal ions and ligand 4,4'-bis(imidazol-1-yl)biphenyl (L) were reported.

\footnotetext{
*E-mail: tlhu@nankai.edu.cn

Received January 24, 2013; published March 26, 2013.

Supporting information for this article is available free of charge via the Internet at http://sioc-journal.cn

Project supported by the National Natural Science Foundation of China (Nos. 21031002, 51073079) and the Natural Science Fund of Tianjin, China (No. 11JCYBJC04100).

项目受国家自然科学基金(Nos. 21031002, 51073079)和天津市自然科学基金(No. 11JCYBJC04100)资助.
} 


\section{Results and discussion}

\subsection{Crystal structure}

Single-crystal X-ray diffraction analysis reveals that complexes $\mathbf{1} \sim \mathbf{3}$ are isomorphous, and thus only the structure of 1 is presented herein as an example. Complex $\mathbf{1}$ crystallizes in the triclinic space group $P-1$. The asymmetric unit consists of two crystallographically independent $\mathrm{Co}^{\mathrm{II}}$ centers, two and a half L ligands, and four azide anions. Figure 1a illustrates the coordination environment of two unique $\mathrm{Co}^{\mathrm{II}}$ ions. The $\mathrm{Co}(1)$ ion is equatorially coordinated by four $E O$-azide $\mathrm{N}$ atoms, and the axial positions are occupied by two $\mathrm{N}$ atoms from two trans-coordinated $\mathrm{L}$ ligands, forming an octahedral coordination environment. The coordination geometry of $\mathrm{Co}(2)$ ion is also octahedral. Similar to $\mathrm{Co}(1)$ ion, it is also axially coordinated by two $\mathrm{N}$ atoms from two trans-coordinated L ligands. However, it is equatorially surrounded by two $E O$-azide anions, one monodentate azide anion, and one trans-coordinated L ligand. The lengths of $\mathrm{Co}-\mathrm{N}$ bond are in good agreement with those typically observed (Table S1). ${ }^{[25]}$

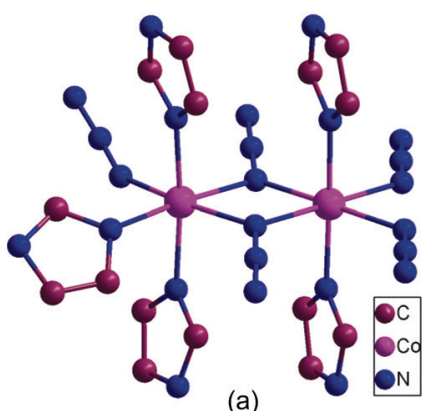

(a)

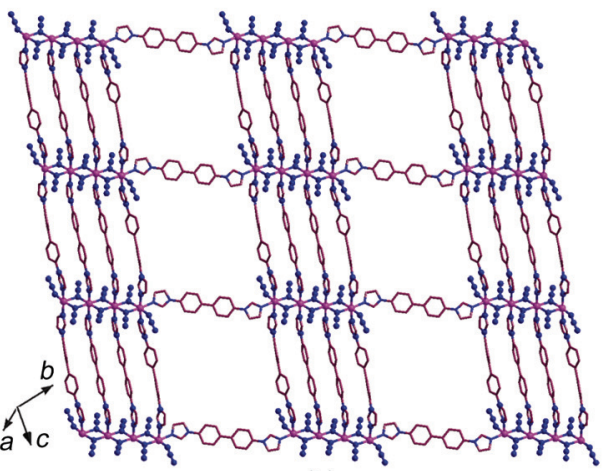

(b)

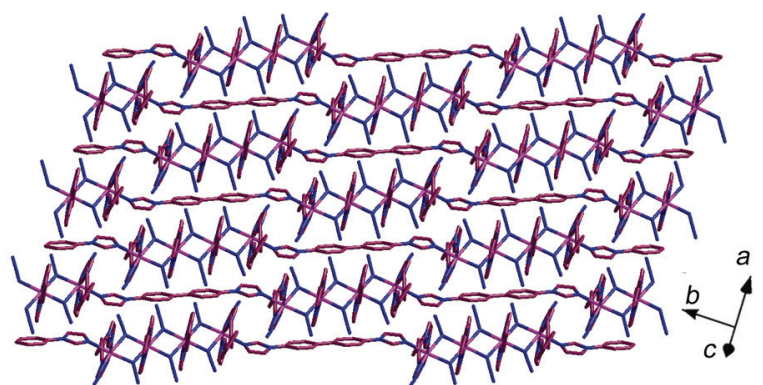

(c)

Figure 1 View of (a) the coordination environments of $\mathrm{Co}^{\mathrm{II}}$ ion (Hydrogen atoms omitted for clarity), (b) the $2 \mathrm{D}(4,4)$ layer $\left[\mathrm{Co}_{4}\left(\mathrm{~N}_{3}\right)_{8}(\mathrm{~L})_{5}\right]_{\infty}$ based on the tetranuclear unit $\left[\mathrm{Co}_{4}\left(\mathrm{~N}_{3}\right)_{8}\right]$ and (c) the packing structure with an $\mathrm{ABAB}$ mode
As shown in Figure $1 \mathrm{~b}$, three pairs of $E O$-azide link adjacent $\mathrm{Co}^{\mathrm{II}}$ ions to form a linear tetranuclear unit $\left[\mathrm{Co}_{4}\left(\mathrm{~N}_{3}\right)_{8}\right]$ with $\mathrm{Co} \cdots$ Co separation of about $3.4 \AA$ (two monodentate azide ions balance the charge). The $\mathrm{Co}-\mathrm{N}-$ Co angles, very important for the magnitude of ferromagnetic coupling, are $100.75(16)^{\circ}, 101.97(16)^{\circ}$ and $103.84(16)^{\circ}$, respectively, in accord with the reported values for the typical EO-azide complexes (Table 2). ${ }^{[26]}$ The linear azide-Co unit is further connected by $\mathrm{L}$ ligands to afford a 2D $(4,4)$ layer $\left[\mathrm{Co}_{4}\left(\mathrm{~N}_{3}\right)_{8}(\mathbf{L})_{5}\right]_{\infty}$ with separations of about 17.7 and $18.0 \AA$ among the $\left[\mathrm{Co}_{4}\left(\mathrm{~N}_{3}\right)_{8}\right]$ units. Furthermore, the neighboring sheets, with the shortest interlayer metal-metal distance of about $9.0 \AA$, are tightly packed in an ABAB manner through intermolecular or van der Waals interactions, which results in a staggering structure towards the plane (131646) (Figure 1c).

For complex 2 , it is worth to mention that the terminal sites of tetranuclear unit are occupied by two nitrate anions. Only the IR spectrum of $\mathbf{2}$ exhibits an absorption band at $c a .1383 \mathrm{~cm}^{-1}$ characteristic of $\mathrm{NO}_{3}^{-}$ion, ${ }^{[27]}$ which is consistent with the existence of nitrate anion in the crystal structure of 2 . Furthermore, three chemical formulas are also confirmed by elemental analysis.

\subsection{Magnetic properties}

The phase purity of bulk materials were confirmed by X-ray powder diffraction (XRPD) experiments (Figure 2). The variable temperature magnetic susceptibility data $(\chi)$ were measured on the powder samples under $1 \mathrm{kOe}$ in the range of $2 \sim 300 \mathrm{~K}$.

The temperature dependence of $\chi_{M} T$ for complex 1 as a $\chi_{M} T$ versus $T$ plots $\left(\chi_{M}\right.$ is the molar magnetic susceptibility) is shown in Figure 3. At room temperature, the $\chi_{M} T$ value is $12.52 \mathrm{~cm}^{3} \cdot \mathrm{K}^{\bullet} \cdot \mathrm{mol}^{-1}$, significantly higher than the spinonly value expected for four isolated $\mathrm{Co}^{\mathrm{II}}$ ions with $S=3 / 2$ $\left(7.50 \mathrm{~cm}^{3} \cdot \mathrm{K} \cdot \mathrm{mol}^{-1} ; g=2.0\right)$, which is attributed to the significant contribution from the unquenched orbital momentum in the octahedral field (the ${ }^{4} T_{1 \mathrm{~g}}$ state). ${ }^{[28]}$ Upon temperature cooling, the $\chi_{M} T$ curve continues to increase to a value of $31.35 \mathrm{~cm}^{3} \cdot \mathrm{K} \cdot \mathrm{mol}^{-1}$ at $9 \mathrm{~K}$, which indicates dominant ferromagnetic (FM) interactions between $\mathrm{Co}^{\mathrm{II}}$ ions. Below this temperature, due to antiferromagnetic (AFM) interaction between $\mathrm{Co}_{4}$ units and/or zero-field splitting, the $\chi_{M} T$ value decreases sharply to $29.10 \mathrm{~cm}^{3} \cdot \mathrm{K} \cdot \mathrm{mol}^{-1}$ at 2 $\mathrm{K}$. Fitting of the $\chi_{M}{ }^{-1}-T$ data above $90 \mathrm{~K}$ with Curie-Weiss law gives a $C$ of $11.28 \mathrm{~cm}^{3} \cdot \mathrm{K} \cdot \mathrm{mol}^{-1}$ and $\theta$ of $34.94 \mathrm{~K}$. The positive $\theta$ value indicates the FM coupling between $\mathrm{Co}^{\text {II }}$ ions, and $C$ value is as expected for the tetranuclear cluster. ${ }^{[29]}$

To examine the long-range ordering, the temperature dependency of alternating-current (ac) magnetic susceptibility was collected at an ac field of 3.5 Oe with different oscillating frequencies $(100 \mathrm{~Hz})$. However, no peak of in-of-phase signal $\left(\chi^{\prime}\right)$ is observed, and the value of out-ofphase signal $\left(\chi^{\prime \prime}\right)$ is zero, indicating no frequency-dependent properties and no long-range ordering (Figure S1).

In order to interpret the magnetic behaviour reasonably, we have assumed two different $J$ values (Figure 4). Indeed, the tetranuclear unit is centrosymmetric. The central part has distances and angles slightly different from those of the terminal moieties. However, for the present linear 

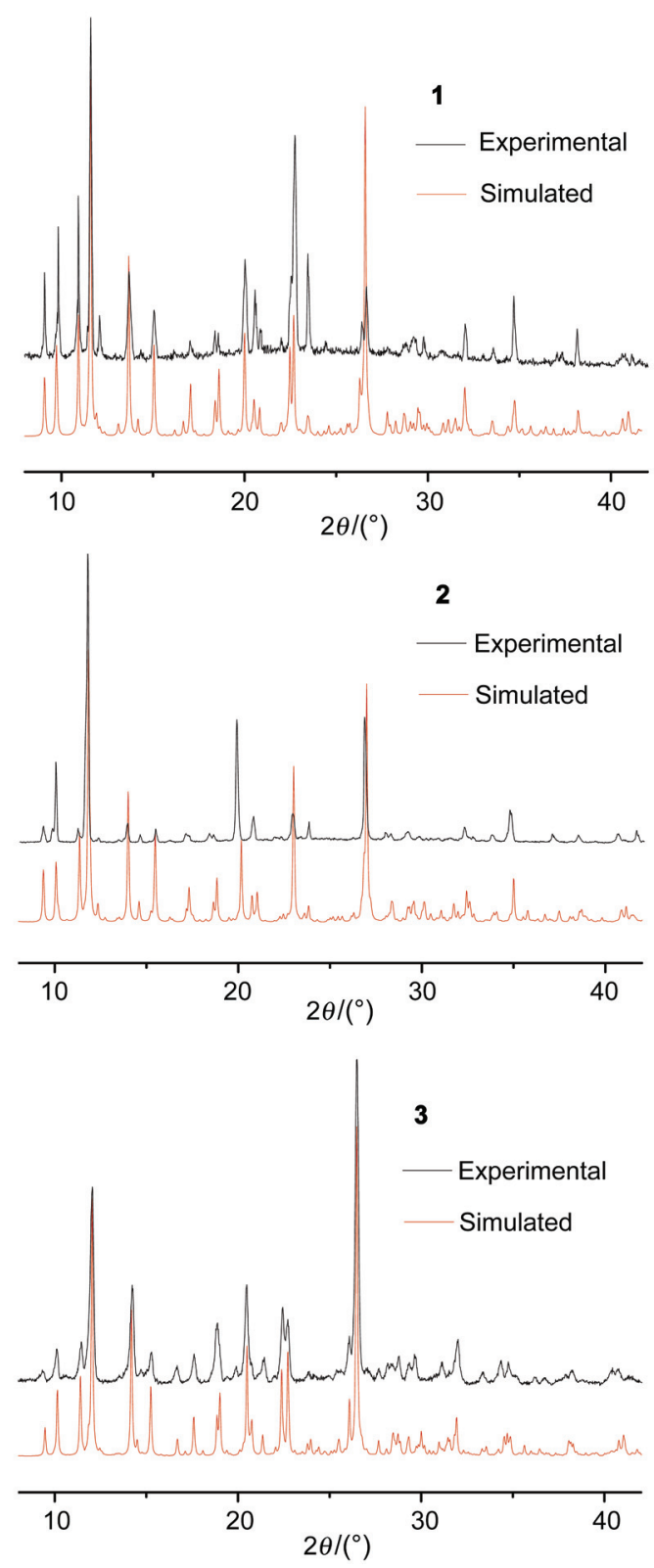

Figure 2 The experimental and simulated XRPD patterns for $\mathbf{1} \sim \mathbf{3}$

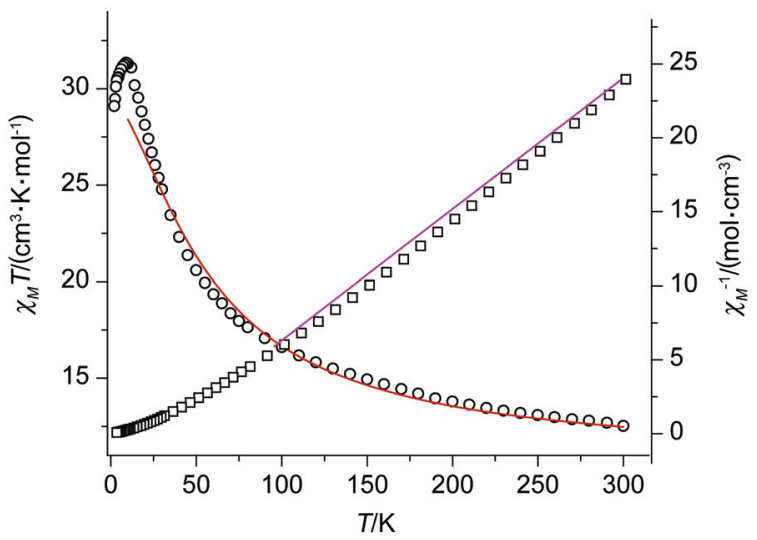

Figure 3 Thermal dependence of $\chi_{M} T$ and $1 / \chi_{M}$ for complex 1, and their corresponding theoretical curves four-spin system, the Kambe vector-coupling method cannot be employed to analyze the variable-temperature susceptibility data. ${ }^{[30]}$ Thus the magnetism package MAGPACK $^{[31]}$ based on the isotropic Hamiltonian given in Eq. (1) has been used if ignoring the orbital momentum.

$$
\hat{H}=-2 J_{1} \hat{S}_{1} \hat{S}_{2}-2 J_{2} \hat{S}_{2} \hat{S}_{3}-2 J_{1} \hat{S}_{3} \hat{S}_{4}
$$

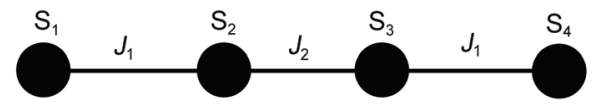

Figure 4 The magnetic pathways for the tetranuclear unit

Magnetic data $(10 \sim 300 \mathrm{~K})$ were fitted and resulted in the best-fit parameters $g_{\mathrm{Co}}=2.30, J_{1}=12.15 \mathrm{~cm}^{-1}$, and $J_{2}$ $=8.62 \mathrm{~cm}^{-1}$. The FM nature of $J_{1}$ and $J_{2}$ is surely attributed to the double $E O$-azido bridge and the little $\mathrm{M}-\mathrm{N}_{3}-\mathrm{M}$ angle of $101.97(16)^{\circ}, 100.75(16)^{\circ}$ and $103.84(16)^{\circ}{ }^{[14]}$

The magnetic property of complex 2 as a $\chi_{M} T$ vs $T$ plots is shown in Figure 5 inset. The value of $\chi_{M} T$ at $300 \mathrm{~K}$ is $5.44 \mathrm{~cm}^{3} \cdot \mathrm{K} \cdot \mathrm{mol}^{-1}$, which is in agreement with the expected for four $\mathrm{Ni}^{\mathrm{II}}$ ions with $S=1$ and $g=2.3$. $^{[32]}$ The $\chi_{M} T$ value increases smoothly from room temperature until 45 $\mathrm{K}$ and then sharply reach a maximum value of 11.18 $\mathrm{cm}^{3} \cdot \mathrm{K} \cdot \mathrm{mol}^{-1}$ at $5 \mathrm{~K}$ upon cooling, which is due to the FM coupling within the $\mathrm{Ni}_{4}$ unit. Below $5 \mathrm{~K}$, the $\chi_{M} T$ value drops to $8.89 \mathrm{~cm}^{3} \cdot \mathrm{K} \cdot \mathrm{mol}^{-1}$ at $2 \mathrm{~K}$, which is attributed to zero-field splitting of $\mathrm{Ni}^{\mathrm{II}}$ ions and/or AFM coupling between $\mathrm{Ni}_{4}$ units. Fitting of the $\chi_{M}{ }^{-1}-T$ data above $75 \mathrm{~K}$ with Curie-Weiss law gives a $C$ of $5.07 \mathrm{~cm}^{3} \cdot \mathrm{K}^{\prime} \cdot \mathrm{mol}^{-1}$ and a $\theta$ of $18.67 \mathrm{~K}$. The positive value of $\theta$ indicates the FM coupling between $\mathrm{Ni}^{\mathrm{iI}}$ ions.

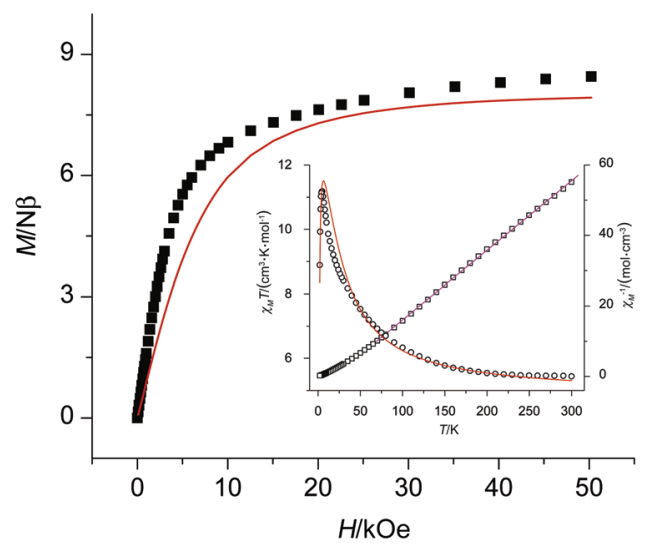

Figure $5 M$ vs $H$ plots of complex 2 at $2.0 \mathrm{~K}$. The inset shows $\chi_{M} T$ vs $T$ plots (o) at $1 \mathrm{kOe}$ and $1 / \chi_{M}$ vs $T$ plots ( $\square$ ) of the complex 2 , and their corresponding theoretical curves

At $2 \mathrm{~K}$, the $M$ versus $H$ measurement of 2 from 0 to 50 $\mathrm{kOe}$ is given in Figure 5. The $M$ values increase quickly at low field, which implies the presence of the ferromagnetic interactions. A magnetization of $8.46 \mathrm{~N} \beta$ is reached at 5.0 $\mathrm{T}$, in agreement with $8.0 \mathrm{~N} \beta$ expected for the ferromagnetic arrangement of the spins. For any value of the field, the experimental magnetization is higher than the magnetization calculated with the Brillouin function for $S=4$ $(g=2.0, T=2 \mathrm{~K})$; this is a further confirmation of the ferromagnetic interactions mediated by azide ligands. ${ }^{[33]}$

Similar to 1, complex $\mathbf{2}$ can be also magnetically treated as a tetranuclear nickel cluster in which magnetic coupling 
is mediated through three pairs of $E O$-azido bridges. It is worth mentioning that the zero-field splitting of $\mathrm{Ni}^{\mathrm{II}}$ ion is evident in the low temperature data. Thus the experimental $\chi_{M} T$ data have been fitted using the spin Hamiltonian given in Eq. 2:

$$
\hat{H}=-2 J_{1} \hat{S}_{1} \hat{S}_{2}-2 J_{2} \hat{S}_{2} \hat{S}_{3}-2 J_{1} \hat{S}_{3} \hat{S}_{4}+D \sum_{i}^{4} \hat{S}_{i}^{2}
$$

where $J_{i}$ describes the exchange interactions $\left(J_{1}=\right.$ terminal and $J_{2}=$ central) and $D$ implies the zero-field splitting of the Ni(II) ion (assuming to be identical for the four ions). The best MAGPACK simulation affords the magnetic parameters $g_{\mathrm{Ni}}=2.20, J_{1}=10.00 \mathrm{~cm}^{-1}$, and $J_{2}=9.53 \mathrm{~cm}^{-1}$, and $|D|=2.65 \mathrm{~cm}^{-1}$ (single ion). The FM nature of $J_{1}$ and $J_{2}$ is surely attributed to the $E O$-azido bridges which will mediate the ferromagnetic coupling regardless of the Ni-N-Ni angle. ${ }^{[34,35]}$

For complex 3, the $\chi_{M} T$ value of $19.1 \mathrm{~cm}^{3} \cdot \mathrm{K} \cdot \mathrm{mol}^{-1}$ at $300 \mathrm{~K}$ is in very good accordance for four non-interacting metal centers of $\mathrm{Mn}^{2+}$ with $S=5 / 2$ and $g=2.0 .^{[36]}$ The $\chi_{M} T$ values gradually increase with temperature cooling down reaching a maximum of $46.6 \mathrm{~cm}^{3} \cdot \mathrm{K} \cdot \mathrm{mol}^{-1}$ at $2 \mathrm{~K}$, which is due to the dominant FM interactions within the $\mathrm{Mn}_{4}$ cluster (Figure 6). Fitting of the $\chi_{M}{ }^{-1}-T$ data above $30 \mathrm{~K}$ with $\mathrm{Cu}-$ rie-Weiss law gives a $C$ of $18.70 \mathrm{~cm}^{3} \cdot \mathrm{K}^{\prime} \cdot \mathrm{mol}^{-1}$ and a $\theta$ of $5.88 \mathrm{~K}$. The positive value of $\theta$ indicates the FM coupling between $\mathrm{Mn}^{\mathrm{II}}$ ions.

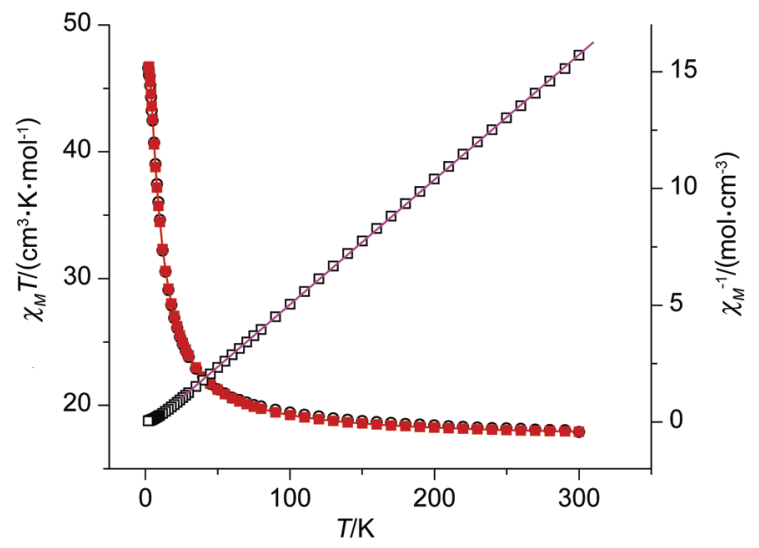

Figure 6 Thermal dependence of $\chi_{M} T$ and $1 / \chi_{M}$ for complex $\mathbf{3}$, and their corresponding theoretical curves

In order to interpret the magnetic behaviour reasonably, we have also assumed two different $J$ values. With this same hypothesis as presented in complex $\mathbf{2}$, the magnetic data of $\mathbf{3}$ were well fitted using the $2 J$ mode based on the spin Hamiltonian of Eq. 2. The best fit to the experimental curve by means of the MAGPACK program gave the following values: $J_{1}=+0.49 \mathrm{~cm}^{-1}, J_{2}=+2.27 \mathrm{~cm}^{-1}, g_{\mathrm{Mn}}=$ 1.99 and $|D|=0.36 \mathrm{~cm}^{-1}$ (single ion). The fitting results indicate weak FM coupling, in agreement with the presence of two azido bridging ligands in end-on coordination mode.

\section{Conclusions}

In summary, three isomorphous coordination polymers, $\mathbf{1} \sim \mathbf{3}$, have been obtained by introducing different divalent metal ions $\left(\mathrm{Co}^{\mathrm{II}}, \mathrm{Ni}^{\mathrm{II}}\right.$ and $\left.\mathrm{Mn}^{\mathrm{II}}\right)$ into the system of $\mathrm{NaN}_{3}$ and $\mathbf{L}$. Three complexes exhibit similar 2D $(4,4)$ layers based on a series of tetranuclear units bridged by the $E O$-azido ion. The tetranuclear clusters are arrayed in a linear mode, which is firstly observed in the azido compounds. Magneto-structural correlations have been studied, and the results reveal that the dominant FM coupling in the complexes is conducted by the $E O$-azido linker. The corresponding exchange coupling constants have been estimated by using the MAGPACK program to fit the experimental data, which also confirm the FM interactions.

\section{Experimental section}

\subsection{Materials and general methods}

All the solvents and reagents for synthesis were commercially available and used as received. Ligand $\mathbf{L}$ was synthesized according to the literature. ${ }^{[22]}$ Elemental analyses was performed on a Perkin-Elmer 240C analyzer. IR spectra were measured on a TENSOR 27 (Bruker) FT-IR spectrometer with $\mathrm{KBr}$ pellets. The X-ray powder diffraction (XRPD) was recorded on a Rigaku D/Max-2500 diffractometer at $40 \mathrm{kV}, 100 \mathrm{~mA}$ for a $\mathrm{Cu}$-target tube and a graphite monochromater. Magnetic data were collected using crushed crystals of the sample on a Quantum Design MPMS-XL SQUID magnetometer equipped with a $5 \mathrm{~T}$ magnet. The data were corrected using Pascal's constants to calculate the diamagnetic susceptibility, and an experimental correction for the sample holder was applied.

\subsection{Synthesis of complexes $1 \sim 3$}

$\left[\mathbf{C o}_{2}\left(\mathbf{N}_{3}\right)_{4}(\mathbf{L})_{2.5}\right]_{\infty}(\mathbf{1})$. The complex was synthesized by the solvothermal method. The suspension of $\mathrm{Co}\left(\mathrm{NO}_{3}\right)_{2} \cdot 6 \mathrm{H}_{2} \mathrm{O}(0.12 \mathrm{mmol}), \mathrm{NaN}_{3}(0.3 \mathrm{mmol})$ and $\mathbf{L}(0.1$ $\mathrm{mmol})$ in $10 \mathrm{~mL}$ component solvent $\left(V_{\mathrm{H}_{2} \mathrm{O}}: V_{\mathrm{C}_{2} \mathrm{H}_{5} \mathrm{OH}}=3\right.$ : 4) was sealed in a Teflon-lined autoclave and heated to 140 ${ }^{\circ} \mathrm{C}$ for $2 \mathrm{~d}$. After the autoclave was cooled to room temperature at $10{ }^{\circ} \mathrm{C} \cdot \mathrm{h}^{-1}$, purple block crystals suitable for single crystal X-ray crystallographic analysis were obtained. The mother liquor was decanted, and the crystals were rinsed three times with ethanol $(8 \mathrm{~mL} \times 3)$ and dried in air for $2 \mathrm{~h}$. Yield: $c a$. $30 \%$ based on L. IR (KBr) $v$ : $3421 \mathrm{~s}, 3138 \mathrm{~m}, 2071 \mathrm{~s}, 2039 \mathrm{~s}, 1607 \mathrm{w}, 1516 \mathrm{~s}, 1412 \mathrm{w}$, $1338 \mathrm{w}, 1305 \mathrm{~m}, 1253 \mathrm{~m}, 1125 \mathrm{w}, 1101 \mathrm{w}, 1066 \mathrm{~m}, 960 \mathrm{w}$, $849 \mathrm{w}, 815 \mathrm{~m}, 736 \mathrm{w}, 648 \mathrm{~m} \mathrm{~cm}^{-1}$. Anal. calcd for $\mathrm{C}_{45} \mathrm{H}_{35} \mathrm{Co}_{2} \mathrm{~N}_{22}$ : C 53.95, H 3.52, N 30.76; found C 53.80, $\mathrm{H} 3.65, \mathrm{~N} 30.65$.

$\left[\mathbf{N i}_{2}\left(\mathbf{N}_{3}\right)_{3}\left(\mathbf{N O}_{3}\right)(\mathbf{L})_{2.5}\right]_{\infty}(\mathbf{2})$. Single crystals of $\mathbf{2}$ suitable for X-ray analysis were obtained by the similar method as described above for 1 . Yield: $c a$. $35 \%$ based on $\mathbf{L}$. IR $(\mathrm{KBr}) v: 3438 \mathrm{~m}, 3124 \mathrm{w}, 2069 \mathrm{~s}, 1607 \mathrm{w}, 1517 \mathrm{~s}, 1417 \mathrm{w}$, $1383 \mathrm{~m}, 1348 \mathrm{w}, 1306 \mathrm{~m}, 1250 \mathrm{w}, 1127 \mathrm{w}, 1102 \mathrm{w}, 1068 \mathrm{~m}$, $960 \mathrm{w}, 815 \mathrm{~m}, 736 \mathrm{w}, 654 \mathrm{w}, 517 \mathrm{w} \mathrm{cm} \mathrm{c}^{-1}$. Anal. calcd for $\mathrm{C}_{45} \mathrm{H}_{35} \mathrm{~N}_{20} \mathrm{Ni}_{2} \mathrm{O}_{3}$ : C 52.92, H 3.45, N 27.43; found C 53.08, H 3.51, N 27.56.

$\left[\mathbf{M n}_{2}\left(\mathbf{N}_{3}\right)_{4}(\mathbf{L})_{2.5}\right]_{\infty}(3)$. This complex was prepared by the layering method. A buffer layer of $\mathrm{H}_{2} \mathrm{O}: \mathrm{C}_{2} \mathrm{H}_{5} \mathrm{OH}(V: V$ $=1: 1,8 \mathrm{~mL}$ ) was carefully layered over a solution of $\mathrm{MnCl}_{2} \cdot 4 \mathrm{H}_{2} \mathrm{O}(0.06 \mathrm{mmol})$ in $\mathrm{H}_{2} \mathrm{O}(6 \mathrm{~mL})$. Then a solution of $\mathbf{L}(0.05 \mathrm{mmol})$ and $\mathrm{NaN}_{3}(0.1 \mathrm{mmol})$ in $\mathrm{C}_{2} \mathrm{H}_{5} \mathrm{OH}(6 \mathrm{~mL})$ was layered over the buffer layer. After $c a$. three weeks, 
colorless prism crystals appeared at the boundary. Yield: ca. $15 \%$ based on L. IR (KBr) v: $3358 \mathrm{w}, 3140 \mathrm{w}, 2077 \mathrm{~s}$, $2045 \mathrm{~s}, 1607 \mathrm{w}, 1518 \mathrm{~s}, 1413 \mathrm{w}, 1333 \mathrm{w}, 1306 \mathrm{~m}, 1256 \mathrm{~m}$, $1123 \mathrm{w}, 1068 \mathrm{~m}, 961 \mathrm{w}, 929 \mathrm{w}, 849 \mathrm{w}, 815 \mathrm{~m}, 736 \mathrm{w}, 649 \mathrm{w}$, $517 \mathrm{w} \mathrm{cm}{ }^{-1}$. Anal. calcd for $\mathrm{C}_{45} \mathrm{H}_{35} \mathrm{Mn}_{2} \mathrm{~N}_{22}$ : C 54.39, H 3.55, N 31.01; found C 54.56, H 3.48, N 31.15.

\subsection{X-ray crystallographic measurements}

X-ray single crystal diffraction data of complexes $1 \sim 3$ were collected on a Rigaku MM-007/Saturn 70 with graphite monochromatic Mo-K $\alpha$ radiation $(\lambda=0.71073 \AA)$. The program SAINT ${ }^{[23]}$ was used for integration of the diffraction profiles. All the structures were solved by direct methods using the SHELXS program of the SHELXTL package and refined by full-matrix least-squares methods with SHELXL. ${ }^{[24]}$ Metal atoms in each complex were located from the $E$-maps and other non-hydrogen atoms were located in successive difference Fourier syntheses. Excluded in some disordered parts, mostly non-hydrogen atoms were refined with anisotropic thermal parameters on $F^{2}$. The hydrogen atoms of the ligands were generated theoretically onto the specific atoms and refined isotropically. In complexes $\mathbf{1}$ and $\mathbf{3}$, one fifth of ligand molecules were disordered and split into two parts for each disordered atom. Further details for structural analysis are summarized in Table 1, and selected bond lengths and angles are listed in Table 2.

Table 1 Crystal data and structure refinement parameters

\begin{tabular}{|c|c|c|c|}
\hline Formula & $\mathrm{C}_{45} \mathrm{H}_{35} \mathrm{Co}_{2} \mathrm{~N}_{22}(\mathbf{1})$ & $\mathrm{C}_{45} \mathrm{H}_{35} \mathrm{Ni}_{2} \mathrm{~N}_{20} \mathrm{O}_{3}(\mathbf{2})$ & $\mathrm{C}_{45} \mathrm{H}_{35} \mathrm{Mn}_{2} \mathrm{~N}_{22}(\mathbf{3})$ \\
\hline F.W. & 1001.81 & 1021.35 & 993.83 \\
\hline Space group & $P-1$ & $P-1$ & $P-1$ \\
\hline$a / \AA$ & $9.5895(19)$ & $9.6298(19)$ & $9.5692(19)$ \\
\hline$b / \AA$ & $14.091(3)$ & $14.036(3)$ & $14.241(3)$ \\
\hline$c / \AA$ & $16.369(3)$ & $16.269(3)$ & $16.451(3)$ \\
\hline$\alpha /\left(^{\circ}\right)$ & $107.74(3)$ & 107.91(3) & $106.86(3)$ \\
\hline$\beta /\left(^{\circ}\right)$ & $98.30(3)$ & $98.39(3)$ & $97.40(3)$ \\
\hline$\gamma\left(\left(^{\circ}\right)\right.$ & $96.60(3)$ & $95.69(3)$ & $98.01(3)$ \\
\hline$V / \AA^{3}$ & $2054.8(7)$ & $2045.7(7)$ & $2090.4(7)$ \\
\hline$Z$ & 2 & 2 & 2 \\
\hline$D /\left(\mathrm{g} \bullet \mathrm{cm}^{-3}\right)$ & 1.619 & 1.658 & 1.579 \\
\hline$\mu / \mathrm{mm}^{-1}$ & 0.875 & 0.994 & 0.671 \\
\hline$F(000)$ & 1026 & 1050 & 1018 \\
\hline$R_{\text {(int) }}$ & 0.0541 & 0.0523 & 0.0926 \\
\hline GOF & 1.112 & 1.074 & 0.987 \\
\hline$R^{a} / \mathrm{w} R^{b}$ & $0.0689 / 0.1528$ & $0.0568 / 0.1993$ & $0.1220 / 0.2834$ \\
\hline
\end{tabular}

Table 2 The important bond lengths $(\AA)$ and angles $\left({ }^{\circ}\right)$ for $\mathbf{1} \sim \mathbf{3}^{a}$

\begin{tabular}{llll}
\hline $\mathrm{M}=$ & $\mathrm{Co}^{\mathrm{II}}$ & $\mathrm{Ni}^{\mathrm{II}}$ & $\mathrm{Mn}^{\mathrm{II}}$ \\
\hline $\mathrm{M}(1)-\mathrm{N}(11)$ & $2.171(4)$ & $2.136(4)$ & $2.298(6)$ \\
$\mathrm{M}(1)-\mathrm{N}(14)$ & $2.198(4)$ & $2.113(4)$ & $2.314(6)$ \\
$\mathrm{M}(1)-\mathrm{N}(17)$ & $2.147(4)$ & $2.168(4)$ & $2.211(6)$ \\
$\mathrm{M}(2)-\mathrm{N}(14)$ & $2.214(4)$ & $2.146(4)$ & $2.303(6)$ \\
$\mathrm{M}(2)-\mathrm{N}(17)$ & $2.171(4)$ & $2.154(4)$ & $2.289(6)$ \\
\hline
\end{tabular}

Continued

\begin{tabular}{llll}
\hline $\mathrm{M}=$ & $\mathrm{Co}^{\mathrm{II}}$ & $\mathrm{Ni}^{\mathrm{II}}$ & $\mathrm{Mn}^{\mathrm{II}}$ \\
\hline $\mathrm{M}(1)-\mathrm{N}(11)-\mathrm{M}(1) \# 1$ & $101.97(16)$ & $102.70(16)$ & $99.8(3)$ \\
$\mathrm{M}(1)-\mathrm{N}(14)-\mathrm{M}(2)$ & $100.75(16)$ & $103.80(17)$ & $99.4(2)$ \\
$\mathrm{M}(1)-\mathrm{N}(17)-\mathrm{M}(2)$ & $103.84(16)$ & $101.69(16)$ & $102.9(2)$ \\
$\mathrm{M}(1) \cdots \mathrm{M}(1) \# 1$ & $3.380(4)$ & $3.342(4)$ & $3.485(6)$ \\
$\mathrm{M}(1) \cdots \mathrm{M}(2)$ & $3.399(4)$ & $3.352(4)$ & $3.520(6)$ \\
\hline
\end{tabular}

${ }^{a}$ Symmetry mode: $\# 1,-x+1,-y+2,-z+1$.

Supporting Information: X-ray crystallographic data for $\mathbf{1}$ and $\mathbf{2}$ in CIF format, selected bond lengths and angles, and the ac susceptibility components of $\mathbf{1}$.

\section{Acknowledgement} sion.

We thank Professor Joan Ribas for the magnetic discus-

\section{References}

[1] Toma, L. M.; Ruiz-Pérez, C.; Pasán, J.; Wernsdorfer, W.; Lloret, F.; Julve, M. J. Am. Chem. Soc. 2012, 134, 15265.

[2] Kurmoo, M. Chem. Soc. Rev. 2009, 38, 1353.

[3] Bagai, R.; Christou, G. Chem. Soc. Rev. 2009, 38, 1011.

[4] Aromí, G.; Aguilà, D.; Gamez, P.; Luis, F.; Roubeau, O. Chem. Soc. Rev. 2012, 41, 537.

[5] Sanvito, S. Chem. Soc. Rev. 2011, 40, 3336.

[6] Leng, J.; Liu, J.; Tong, M. Chem. Commun. 2012, 48, 5286.

[7] Liu, R.; Li, L.; Wang, X.; Yang, P.; Wang, C.; Liao, D.; Sutter, J. Chem. Commun. 2010, 46, 2566.

[8] Jiang, S. D.; Wang, B. W.; Sun, H. L.; Wang, Z. M.; Gao, S. J. Am. Chem. Soc. 2011, 133, 4730.

[9] Yang, E. C.; Liu, Z. Y.; Wu, X. Y.; Zhao, X. J. Chem. Commun. 2011, 47, 8629.

[10] Yao, M. X.; Zheng, Q.; Cai, X. M.; Li, Y. Z.; Song, Y.; Zuo, J. L. Inorg. Chem. 2012, 51, 2140.

[11] Miller, J. S. Chem. Soc. Rev. 2011, 40, 3266.

[12] Xu, G. C.; Zhang, W.; Ma, X. M.; Chen, Y. H.; Zhang, L.; Cai, H. L.; Wang, Z. M.; Xiong, R. G.; Gao, S. J. Am. Chem. Soc. 2011, 133,14948 .

[13] Huang, Y. G.; Jiang, F. L.; Hong, M. C. Coord. Chem. Rev. 2009, 253, 2814.

[14] Zeng, Y. F.; Hu, X.; Liu, F. C.; Bu, X. H. Chem. Soc. Rev. 2009, 38, 469.

[15] Ribas, J.; Escuer, A.; Monfort, M.; Vicente, R.; Cortés, R.; Lezama, L.; Rojo, T. Coord. Chem. Rev. 1999, 193 195, 1027.

[16] Zhao, J. P.; Hu, B. W.; Yang, Q.; Liu, F. C.; Hu, T. L.; Bu, X. H. Chin. Sci. Bull. 2009, 54, 4303

[17] Zhang, X. F.; Yang, Q.; Zhao, J. P.; Hu, T. L.; Chang, Z.; Bu, X. H. Sci. China Chem. 2011, 54, 1446.

[18] Gao, E. Q.; Liu, P. P.; Wang, Y. Q.; Yue, Q.; Wang, Q. L. Chem. Eur. J. 2009, 15, 1217.

[19] Su, Z.; Bai, Z. S.; Fan, J.; Xu, J.; Sun, W. Y. Cryst. Growth Des. 2009, 9, 5190 .

[20] Li, Z. X.; Zhao, J. P.; Sañudo, E. C.; Ma, H.; Pan, Z. D.; Zeng, Y. F.; Bu, X. H. Inorg. Chem. 2009, 48, 11601.

[21] Li, Z. X.; Ma, H.; Chen, S. L.; Pan, Z. D.; Zeng, Y. F.; Wang, X. L.; $\mathrm{Bu}, \mathrm{X}$. H. Dalton Trans. 2011, 40, 31.

[22] Fan, J.; Hanson, B. E. Chem. Commun. 2005, 2327.

[23] SAINT Software Reference Manual; Bruker AXS: Madison, WI, 1998.

[24] Sheldrick, G. M.; SHELXTL NT Version 5.1, University of Göttingen, Germany, 1997.

[25] Wang, X. L.; Mu, B.; Lin, H. Y.; Yang, S.; Liu, G. C.; Tian, A. X.; Zhang, J. W. Dalton Trans. 2012, 41, 11074.

[26] Li, Z. X.; Zeng, Y. F.; Ma, H.; Bu, X. H. Chem. Commun. 2010, 46, 8540 .

[27] Li, C. P.; Chen, J.; Yu, Q.; Du, M. Cryst. Growth Des. 2010, 10, 1623.

[28] Yang, Q.; Zhao, J. P.; Song, W. C.; Bu, X. H. Dalton Trans. 2012, 


\section{1,6272 .}

[29] Zeng, M. H.; Yao, M. X.; Liang, H.; Zhang, W. X.; Chen, X. M. Angew. Chem., Int. Ed. 2007, 46, 1832.

[30] Kambe, K. J. Phys. Soc. Jpn. 1950, 5, 48.

[31] Borrás-Almenar, J. J.; Clemente-Juan, J. M.; Coronado, E.; Tsukerblat, B. S. J. Comput. Chem. 2001, 22, 985.

[32] Zhou, Y. L.; Zeng, M. H.; Liu, X. C.; Liang, H.; Kurmo, M. Chem. Eur. J. 2011, 17, 14084.
[33] Fellah, F. Z. C.; Costes, J. P.; Dahan, F.; Duhayon, C.; Novitchi, G.; Tuchagues, J. P.; Vendier, L. Inorg. Chem. 2008, 47, 6444.

[34] Ruiz, E.; Cano, J.; Alvarez, S.; Alemany, P. J. Am. Chem. Soc. 1998, 120,11122

[35] Mialane, P.; Dolbecq, A.; Rivière, E.; Marrot, J.; Sècheresse, F. Angew. Chem., Int. Ed. 2004, 43, 2274.

[36] Yang, P. P.; Song, X. Y.; Liu, R. N.; Li, L. C.; Liao, D. Z. Dalton Trans. 2010, 39, 6285.

(Cheng, F.) 